\title{
Poly(dopamine) grafted bio-silica composite with tetraethylenepentamine ligands for enhanced adsorption of pollutants
}

\author{
Tugce A. Arica ${ }^{a, *}$, Merve Kuman ${ }^{b}$, Ozgul Gercel ${ }^{b}$, Erhan Ayas ${ }^{c}$ \\ a Department of Material Science and Engineering, Izmir Institute of Technology, Urla 35430, Izmir, Turkey \\ b Department of Environmental Engineering, Faculty of Engineering, Eskişehir Technical University, 26480 Eskisehir, \\ Turkey \\ c Department of Materials Science and Engineering, Faculty of Engineering, Eskişehir Technical University, 26480 \\ Eskisehir, Turkey
}

\section{A R T I C L E I N F O}

\section{Article history:}

Received 2 September 2018

Received in revised form 22 October

2018

Accepted 2 November 2018

Available online 14 November 2018

Keywords:

Bio-silica

Grafting

Polydopamine

Polyamine ligand

Dye removal

Adsorption

\begin{abstract}
A B S T R A C T
In this study, diatomite fossil particles (i.e., bio-silica) was treated with strong acid solution and coated with polydopamine (bio-silica-PDA) using aqueous-based bioinspired coating method. The bio-silica-PDA was grafted with tetraethylenepentamine (TEPA) ligand to increase binding sites on the material surfaces. The biosilica-PDA-TEPA particles was characterized using Fourier-transform infrared spectroscopy (FTIR), Scanning electron microscope (SEM), X-Ray Diffraction (XRD) and Brunauer-Emmett-Teller (BET) method. The adsorption performance of the biosilica-PDA-TEPA particles was studied using a model dye (i.e., Direct Blue 74; DB-74) from aqueous solutions using biosilica-PDA as a control system. Batch system was used to optimize experimental conditions for the removal of DB-74 dye on the sorbents. The adsorption of DB-74 on the biosilica-PDA-TEPA particles was studied in the $\mathrm{pH}$ range of 2.0-8.0. The amount adsorbed DB-74 dye on the biosilica-PDA-TEPA was $363.3 \mathrm{mg} \mathrm{g}^{-1}$ (using initial dye concentration $1200 \mathrm{mgL}^{-1}, \mathrm{pH} 3.0$ and temperature $25^{\circ} \mathrm{C}$ ). Adsorption of DB-74 dye on biosilica-PDA-TEPA particles fitted well Langmuir model. The equilibrium adsorption time was completed within $10 \mathrm{~min}$ and the experimental data was defined well by the pseudo-second-order model. In addition, the biosilica-PDA-TEPA particles presented a good performance after regeneration. This result show that the presented low-cost porous biosilica-PDA-TEPA particles can be a good candidate as a novel sorbent system for removal of micro-pollutants from wastewaters.
\end{abstract}

(c) 2018 Institution of Chemical Engineers. Published by Elsevier B.V. All rights reserved.

\section{Introduction}

Synthetic organic complex dyes are used in several industries such as textile, plastics, paper, cosmetics etc. (Aksu and Karabayır, 2008; Ibupoto et al., 2018). The effluent from these sites can contain different organic and inorganic pollutants and establish a deoxygenation system by promoting microbial growth. Moreover, dyes solution discharged from these industries have caused serious environment problems due to their high toxicity and carcinogenicity (Yang et al., 2017; Zhang et al., 2018; Ibupoto et al., 2018; Arsalani et al., 2018). The total amount of dyes production in the world were around $700,000 \mathrm{t}$ and about $2.0 \%$ of these dyes are discharged from the textile effluents (Mondal et al., 2017). Therefore, textile dyes are important pollutants and cause colored effluents.

Many physical and chemical methods have been proposed and already industrially implemented to remove colored dye pollutants from wastewater. The removal of organic and inorganic pollutants can be realized by adsorption, membrane separation, filtration, precipitation, or biological methods (Xiong et al., 2018; Vojoudi et al., 2018; Liu et al., 2018). Among them, adsorption process offers many advan-

\footnotetext{
* Corresponding author.

E-mail address: tugcearica@iyte.edu.tr (T.A. Arica).
}

https://doi.org/10.1016/j.cherd.2018.11.003

0263-8762/@ 2018 Institution of Chemical Engineers. Published by Elsevier B.V. All rights reserved. 
tages such as it is simple and reliable, and energy efficient (Aksu and Karabayır, 2008; Ibupoto et al., 2018). However, high-capacity, selective, and recyclable adsorbents have to be designed for this method. In recent years, silica based adsorbents have been utilized after decoration with different functional groups for removal of micro-pollutants from wastewaters. These materials have been also used for gas storage, filtration of juice and clearance of wine (Knoerr et al., 2013; Gao et al., 2018; Arica et al., 2017; Konicki et al., 2018). The modification of the silica based materials with different ligands containing carboxyl, amine, or mixed mode groups are permit their utilization as effective adsorbents in the adsorption technology (Wang et al., 2018; Ghasemi and Karim, 2018). Polyamine ligands are water-soluble cationic molecules which are possesses many primary and secondary amine groups. Polyamine groups decorated adsorbents have been exhibited an exceptional capability for the adsorption of many pollutants from wastewaters (Arica et al., 2017; Vojoudi et al., 2018; Boukoussa et al., 2018). The amine groups of these ligands are easily protonated and the anionic pollutants can be effectively removed via strong electrostatic interaction from the aqueous medium (Srinivasan and Viraraghavan, 2010; Arica et al., 2017).

Diatomic biosilica has been obtained from the natural fossil of diatoms and used as an efficient adsorbent after modification with different functional groups (Knoerr et al., 2013; Grommersch et al., 2018; Li et al., 2017). Recently, a simple mimic of mussel adhesive proteins named as poly(dopamine) have been used for coating of various materials. It was obtained after polymerization of dopamine under mild alkaline and oxidizing environments (Messersmith et al., 2007). The poly(dopamine) coated surfaces were also used as a secondary modification platform for Michael addition or Schiff base reactions (Xu et al., 2018; Zeng et al., 2017). Thus, a thin PDA layer on bio-silica permits the attachment of different ligand with desired functional groups such as amine, sulfate, hydroxyl and carboxyl groups. This coating method has been applied in many research areas such as in nanobiotechnological, biomedical, and environmental. This coating process also has been referred as simple one-step surface modification arrangement (Messersmith et al., 2007).

In the presented study, acid treated diatomic bio-silica was firstly coated with poly(dopamine), then used as a platform for incorporation of a polyamine ligand (i.e., TEPA; bio-silica-PDA-TEPA). The modified adsorbent was used as an efficient adsorbent for removal of a model acidic direct dye from aqueous solutions. The bio-silica-PDA-TEPA particles were characterized by ATR-FTIR, SEM, BET method, X-ray diffraction, and analytical methods. Adsorption kinetics and capacity of the bio-silica-PDA-TEPA particles were studied under different experimental conditions for adsorption of a model dye (i.e., contact times, $\mathrm{pH}$, initial DB-74 concentrations, and adsorbent dosage). Additionally, the adsorption isotherms and kinetics parameters were evaluated using the experimental data.

\section{Materials and methods}

\subsection{Materials}

Tetraethylenepentamine [(TEPA, $\mathrm{H}_{2} \mathrm{~N}-\left(\mathrm{CH}_{2}\right)_{2}-\mathrm{NH}-\left(\mathrm{CH}_{2}\right)_{2}$ $\left.\mathrm{NH}-\left(\mathrm{CH}_{2}\right)_{2}-\mathrm{NH}-\left(\mathrm{CH}_{2}\right)-\mathrm{NH}_{2}\right)$; purity $\left.\left.>85.0 \%\right)\right]$, Tris- $\mathrm{HCl}$ and dopamine hydrochloride (purity $>98 \%$ ) were obtained from Sigma-Aldrich Chem. Direct Blue 74 was obtained from Bursa Dye Chemical Industries (Burboya, Bursa, Turkey). These chemicals were used as supplied without additional refinement. Diatomic earth was obtained as a gift from Karaman Mining Company, Ankara-Kazan, and was used as silicate source after acid treatment. Distilled water was used during these experiments.

\subsection{Acid treatment of raw diatomic earth}

The raw diatomic earth $(20 \mathrm{~g})$ were comminuted in distilled water $(500 \mathrm{~mL})$ and agitated magnetically at $25^{\circ} \mathrm{C}$ for $10 \mathrm{~h}$. Then, it was filtrated using a Buchner funnel, and dried at $110^{\circ} \mathrm{C}$ for $24 \mathrm{~h}$. After that diatomic silica particles were transferred in strong sulfuric acid solution (i.e., $\mathrm{H}_{2} \mathrm{SO}_{4}, 30 \% \mathrm{v} / \mathrm{v}$ ). The mixture was placed on a magnetic stirrer and agitated at $100 \mathrm{rpm}$ at $100^{\circ} \mathrm{C}$ for $4.0 \mathrm{~h}$. Then, the mixture was cooled down to room temperature, and washed with distilled water until the solution $\mathrm{pH}$ reached neutral. The acid treated bio-silica particles were dried at $110^{\circ} \mathrm{C}$ for $24 \mathrm{~h}$.

\subsection{Preparation of poly(dopamine) coated and TEPA grafted diatomic bio-silica}

The surfaces of the acid treated bio-silica particles were coated with poly(dopamine) using the method described by Messersmith et al. 2007. Briefly, bio-silica particles (about 5.0 g) were added to the solution of Tris-HCl buffer (10 mM, pH 8.5, $200 \mathrm{~mL})$, ethanol $(50 \mathrm{~mL})$ and dopamine hydrochloride acid (400 mg) mixture. The medium was continuously stirred at $50^{\circ} \mathrm{C}$ for $24 \mathrm{~h}$. Finally, the poly(dopamine) coated bio-silica particles were collected by filtration and sequentially washed with ethanol $(100 \mathrm{~mL})$ and distilled water, and dried at $50^{\circ} \mathrm{C}$ for $48 \mathrm{~h}$. The poly(dopamine) coated bio-silica particles $(5.0 \mathrm{~g}$ ) were added into the Tris- $\mathrm{HCl}$ ( $\mathrm{pH} 8.5,40 \mathrm{mM}, 200 \mathrm{~mL}$ ) buffer containing tetraethylenepentamine (TEPA) ligand $\left(5 \mathrm{mg} \mathrm{mL}^{-1}\right)$. Then, the mixture was located on a shaker and orbited at $150 \mathrm{rpm}$ and at $55^{\circ} \mathrm{C}$ for $12 \mathrm{~h}$. The bio-silica-PDP-TEPA particles were collected by simple filtration and washed with distilled water $(100 \mathrm{~mL})$ and ethanol $(100 \mathrm{~mL})$. Then, the bio-silica-PDATEPA particles were dried at $50^{\circ} \mathrm{C}$ for $48 \mathrm{~h}$.

The amount of incorporated TEPA ligand on the bio-silica particles was detected by a titrimetric method. About a $0.5 \mathrm{~g}$ of the bio-silica-PDA-TEPA particles was added into a flask containing hydrochloric acid solution $\left(0.1 \mathrm{~mol} \mathrm{~L}^{-1}, 10 \mathrm{~mL}\right)$. The solution was placed and shaken in a water bath at room temperature for $6.0 \mathrm{~h}$. Then, the remaining concentration of $\mathrm{HCl}$ in the solution was detected by titration with $0.02 \mathrm{M} \mathrm{NaOH}$.

\subsection{Adsorption experiments}

Adsorption of Direct Blue 74 (DB-74) on bio-silica-PDA and biosilica-PDA-TEPA particles was performed in a batch system as functions of contact time, sorbent dose, $\mathrm{pH}$, temperature, and initial dye concentration. The DB-74 dye stock solution was prepared in distilled water and containing $2000 \mathrm{mg} / \mathrm{L}$. The range of concentration of the dye was prepared from this stock solution. The influence of $\mathrm{pH}$ on the amount of dye adsorption on the bio-silica-PDA-TEPA particles was studied in the $\mathrm{pH}$ range $2.0-8.0$ for $\mathrm{DB}-74$ dye at $25^{\circ} \mathrm{C}$. The $\mathrm{pH}$ of the adsorption medium was adjusted using $0.1 \mathrm{~mol} \mathrm{~L}^{-1} \mathrm{HCl}$ or $\mathrm{NaOH}$ solution. The dye has sulphate groups (Table S1) and generally exist in sulfonate form. The sulphate group has a $\mathrm{pK}_{\mathrm{a}}$ value of 1.9. On the other hand, at tetraethylenepentamine ligand has net five positive charges until $\mathrm{pH}$ 9.68. The tetraethylenepentamine ligand is completely miscible within aqueous medium and $\mathrm{pK}_{\mathrm{a}}$ values are $\mathrm{pK}_{\mathrm{a} 1}=9.68, \mathrm{pK}_{\mathrm{a} 2}=9.10$, $\mathrm{pK}_{\mathrm{a} 3}=8.08, \mathrm{pK}_{\mathrm{a} 4}=4.72$, and $\mathrm{pK}_{\mathrm{a} 5}=2.98$. The adsorption experiments were realized at $\mathrm{pH}$ between 2.0 and 8.0. The presence of salt on the adsorption efficiency was studied using $\mathrm{NaCl}$ as background electrolyte in the range $0.0-1.0 \mathrm{~mol} \mathrm{~L}^{-1}$. The effect of initial dye concentration on the removal effectiveness on the bio-silica-PDA-TEPA particles was studied in the range of $25-500 \mathrm{mg} \mathrm{L}^{-1}$. The reaction volume of the dye solution was $20 \mathrm{~mL}$, and $50 \mathrm{mg}$ bio-silica-PDA or bio silica-PDA-TEPA particles was used in experiments. The concentration of DB-74 dye in the solution was determined by UV-spectrophotometry. All 


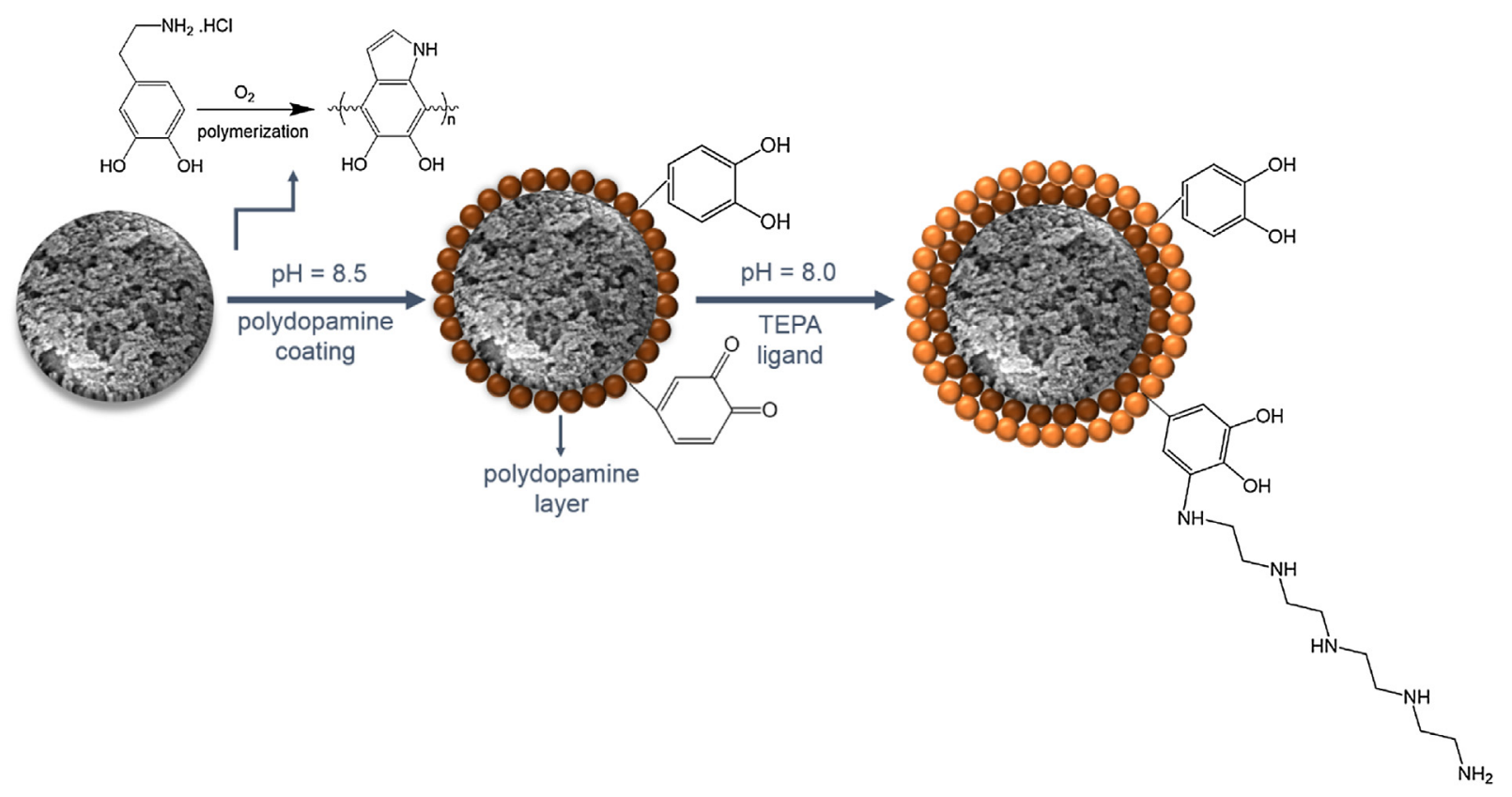

Fig. 1 - Chemistry of preparation of the bio-silica-PDA and bio-silica-PDA-TEPA particles.

measurements were made at $618 \mathrm{~nm}$. The molecular structure and some properties of the DB-74 dye is shown in Table S1.

\subsection{Adsorption-desorption studies}

To control the reusability of the bio-silica-PDA-TEPA particles, adsorption-desorption cycles were repeated 10 times using the same bio-silica-PDA-TEPA particles. Desorption of DB-74 was realized using $\mathrm{NaOH}$ solution $\left(50 \mathrm{mmol}^{-1}\right)$. The dye laden particles were added in desorption medium and agitated at $200 \mathrm{rpm}$ for $2.0 \mathrm{~h}$ at $25^{\circ} \mathrm{C}$. After repeated adsorption/desorption cycle, the biosilica-TETA particles was washed and transferred in to fresh medium for run the subsequent cycle.

\subsection{Characterization of bio-silica based particles}

The free amino group content of the bio-silica-PDA-TEPA particles was determined by potentiometric titration as reported earlier (Bayramoglu et al., 2017; Zeng et al., 2017). The grafting amount (GA) was determined by calculating the amount of increase in the mass on the acid treated biomass using the following equation:

$\mathrm{GA}(\mathrm{mg})=\left[\left(\mathrm{m}_{\mathrm{m}}-\mathrm{m}_{0}\right) / \mathrm{m}_{0}\right] \times 100$

where $\mathrm{M}_{\mathrm{m}}$ and $\mathrm{M}_{0}$ are the mass weight of the bio-silica particles before and after grafting reaction $(\mathrm{g})$, respectively. A $5.0 \mathrm{~g}$ of bio-silica particles were transferred to the reaction Tris$\mathrm{HCl}$ buffer $(200 \mathrm{~mL})$ containing dopamine hydrochloride and stirred for $24 \mathrm{~h}$. After reaction, the bio-silica particles were dried and weighted. The increase in the mass of was calculated above equation.

The scanning electron micrographs of samples were obtained using a JEOL (Model, JSM 5600, Japan) ATR-FT-IR spectra of the bio-silica samples were made in one-bounce ATR mode in a Spectrum 100 FTIR spectrometer (Perkin Elmer Inc., Norwalk, CT, USA) and samples were scanned from 4000 to $525 \mathrm{~cm}^{-1}$.
The specific surface area the total pore volume and the pore size distribution of the bio-silica particles was studied by (Brunauer, Emmett, and Teller) BET method using a Quantachrome Nova $2200 \mathrm{E}$, USA. The $\zeta$ potential is an important parameter for evaluating the net surface charge of an adsorbent in aqueous solution. In a typical experiment, the bio-silica particles $(0.2 \mathrm{~g})$ was added into flasks containing distilled water $(100 \mathrm{~mL})$, stirred magnetically about $1.0 \mathrm{~h}$. The medium $\mathrm{pH}$ was adjusted and then, used to conduct potential measurement with a Zeta-sizer (NanoZS, Malvern Instruments Ltd., Malvern, UK).

Chemical analysis of pristine, acid treated bio-silica and bio-silica-PDA-TEPA particles was studied by x-ray fluorescence technique (ZSX Primus, Rigaku). The phase analysis of the pristine and acid treated bio-silica were analyzed by $\mathrm{x}$-ray diffraction (XRD) technique by using $\mathrm{CuK} \alpha$ radiation, $\lambda=1.541$, between $2 \theta$ of $10-70^{\circ}$ with a 0.02 increment and $2 \%$ min scan speed by MiniFlex 600, Rigaku). The phase match studies of XRD analysis are made based on the XRF characterization results. The Match! software package (Crystal Impact GbR, Bonn, Germany) supported by ICDD PDF-2 Powder Diffraction File as the reference database were used. The diatomic silica particles size were measured with laser diffraction particle size analyzer (Mastersizer 2000, Malvern Instruments, UK).

\section{Results and discussion}

\subsection{Characterization of diatomic bio-silica particles}

The pristine, acid treated and modified diatomic bio-silica samples were characterized by BET, FTIR, zeta potential, XRD, SEM and analytical methods. After acid treatment, the stepwise procedures for the PDA and TEPA grafting of diatomic bio-silica are presented in Fig. 1. The particle size distribution curve and average particle size of the acid treated bio-silica is presented in Fig. S1. The average particle size was found to be $34 \mu \mathrm{m}$, and used in the remaining work without further processing. The polymerization of dopamine over acid treated and cleaned bio-silica was realized in tris-HCl buffer containing dopamine at $50^{\circ} \mathrm{C}$ for $24 \mathrm{~h}$. The PDA layers on the 


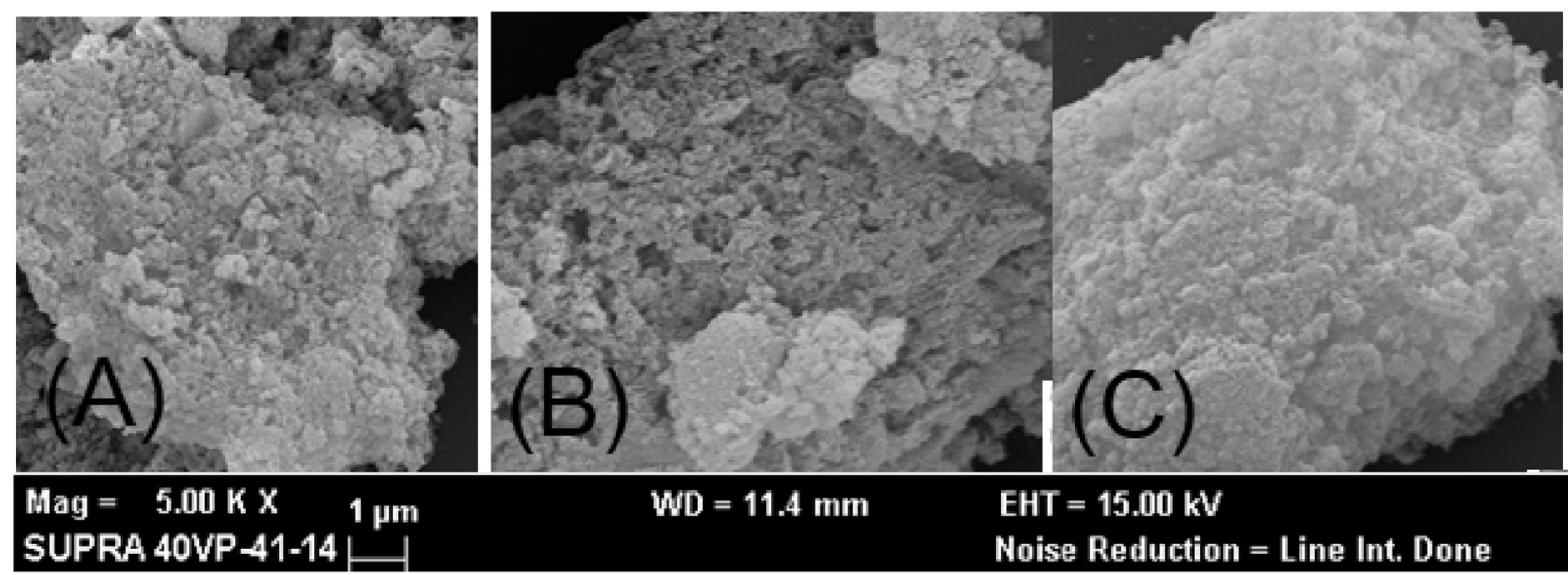

Fig. 2 - SEM micro-grafts of (a) acid treated-bio-silica; (b) bio-silica-PDA; (c) bio-silica-PDA-TEPA particles.

bio-silica surface was easily observed with naked eye from the formation of dark brown color of PDA with time due to polymerization of PDA on the bio-silica surface. As reported earlier, the formation and firm fixation of PDA layers on bio-silica surface can be due to the several noncovalent interactions of PDA with bio-silica surface such hydrogen bonding interaction, $\pi-\pi$ interaction, and electrostatic interaction (Zeng et al., 2017). The reactive properties of the PDA coating permits the post grafting with the compounds containing free primary and secondary amine and thiol groups via Schiff base or Michael addition reactions. In this work, the PDA layers was modified with the tetraethylenepentamine ligand containing both primary and secondary amine groups (Table S1). The grafting of TEPA was realized in tris-HCl buffer as described above. After the grafting reaction, the modified bio-silica particles were cleaned with distilled water. The grafted amount of PDA was found to be $16.8 \mathrm{mgg}^{-1}$.

The energy dispersive X-ray analysis (EDAX) was performed to determine the elemental composition of the pristine, acid treated, and PDA-TEPA modified bio-silica particles. The results of EDAX analysis are depicted in Fig. S2. The elemental compositions are also presented in Table S2. The pristine bio-silica is mainly composed of oxygen, silica, carbon and impurities (i.e., $\mathrm{Ca}, \mathrm{Al}, \mathrm{Mg}, \mathrm{N}, \mathrm{Na}$ ). It should be noted that the amount of the silica percentage of the acid treated biosilica increased compared to pristine bio-silica. Additionally, the amount of carbon and nitrogen content of the bio-silicaPDA-TEPA increased with respect to acid treated bio-silica.

The ATR-FT-IR spectra of the acid treated, PDA and TEPA grafted silica particles samples were obtained in the range of $400-4000 \mathrm{~cm}^{-1}$ (Fig. S2). The broad peak at about $3200-3500 \mathrm{~cm}^{-1}$ can be assigned to the hydroxyl groups at surface silanols groups of acid treated bio-silica (Arica et al., 2017; Jiang et al., 2018). Additionally, the characteristic adsorption peaks of $\mathrm{SiO}_{2}$ can be observed at 810,1150 and $475 \mathrm{~cm}^{-1}$, are due to symmetric stretching of Si-O, asymmetric stretching vibration of $\mathrm{Si}-\mathrm{O}-\mathrm{Si}$ and $\mathrm{Si}-\mathrm{O}-\mathrm{Si}$ deformation, respectively (Fig. S3a). Fig. S3b shows the spectra of PDA grafted bio-silica. The characteristic absorption peaks of PDA are observed at around $3500 \mathrm{~cm}^{-1}$ and centered at $3450 \mathrm{~cm}^{-1}$ due to the phenolic $-\mathrm{OH}$ and $-\mathrm{NH}$ stretching vibration. The presence of additional band at $2925 \mathrm{~cm}^{-1}$ is due to the $\mathrm{CH}$ - stretching of PDA. The peak at $1648 \mathrm{~cm}^{-1}$ can be assigned stretching vibration of aromatic ring and overlapped bending vibration of $\mathrm{N}-\mathrm{H}$. The peaks at 1510 and $1125 \mathrm{~cm}^{-1}$ can be ascribed to $\mathrm{N}-\mathrm{H}$ shearing vibration of the amide group and the $\mathrm{C}-\mathrm{O}$ stretching vibration, respectively (Jiang et al., 2018; Cao et al., 2018). Thus,
Table 1 - Textural parameters of the pristine, acid treated and TEPA and PDA grafted bio-silica samples.

\begin{tabular}{lll} 
Bio-silica samples & $\begin{array}{l}\text { BET surface } \\
\text { area }\left(\mathrm{m}^{2} \mathrm{~g}^{-1}\right)\end{array}$ & $\begin{array}{l}\text { Average pore } \\
\text { diameter }(\mathrm{nm})\end{array}$ \\
\hline Pristine & 87.7 & 2.89 \\
Acid treated & 95.3 & 3.21 \\
TEPA and PDA grafted & 91.6 & 3.05 \\
\hline
\end{tabular}

the presence of the $\mathrm{N}-\mathrm{H}$ vibration of amide groups can show the coating of biosilica with PDA polymer via surface polymerization (Rahouia et al., 2018; Cao et al., 2018). The FTIR spectra of the biosilica-TEPA-PDA display some new peaks compared to those of the acid treated and PDA grafted biosilica (Fig. S3c), including $-\mathrm{CH}_{2}$ stretching at $2945 \mathrm{~cm}^{-1}$ and $-\mathrm{NH}_{2}$ stretching vibration at $1565 \mathrm{~cm}^{-1}$. These results show the success of PDA and TEPA grafting on the diatomic bio-silica.

The measurements of surface area and pore size of the pristine, acid treated and TEPA-PDA grafted diatomic biosilica samples were studied and calculated using BET method. The parameters of these materials are presented in Table 1. According to these results, the pristine bio-silica samples showed smaller surface area and pore volume than those of the acid treated and TEPA-PDA grafted bio-silica. On the other hand, surface area and pore volume of the TEPA-PDA grafted bio-silica was slightly decreased compared to acid treated counterpart. The pore size of the materials was varied between 2.89 and $3.21 \mathrm{~nm}$ indicating all the bio-silica samples have mesoporous textures. After acid treatment, the surface area and pore volume of the bio-silica were significantly increased. The increase in surface area and pore volume of the acid treated bio-silica can be due to the removal of some alkali metal oxide in the vicinity of the pores from the bio-silica particles. On the other hand, the surface and average pore size of the TEPA and PDA grafted bio-silica were decreased compared to acid treated counterpart, these can be caused by accumulation of the polymer and ligand on the surface and pores which can lead to the blocking of the pores.

The surface morphology of the pristine, acid treated and TEPA-PDA grafted bio-silica particles was investigated by SEM (parts A, B and C respectively, of Fig. 2). The SEM micrographs of the pristine, acid treated and TEPA-PDA grafted bio-silica particles showed a difference between their surface morphology and pores. The pores were observed on the surfaces of the pristine and acid treated bio-silica (Fig. 2A and B). After treatment with $\mathrm{H}_{2} \mathrm{SO}_{4}$, the pores were preserved and slightly opened compared with the pristine bio-silica. On the other 


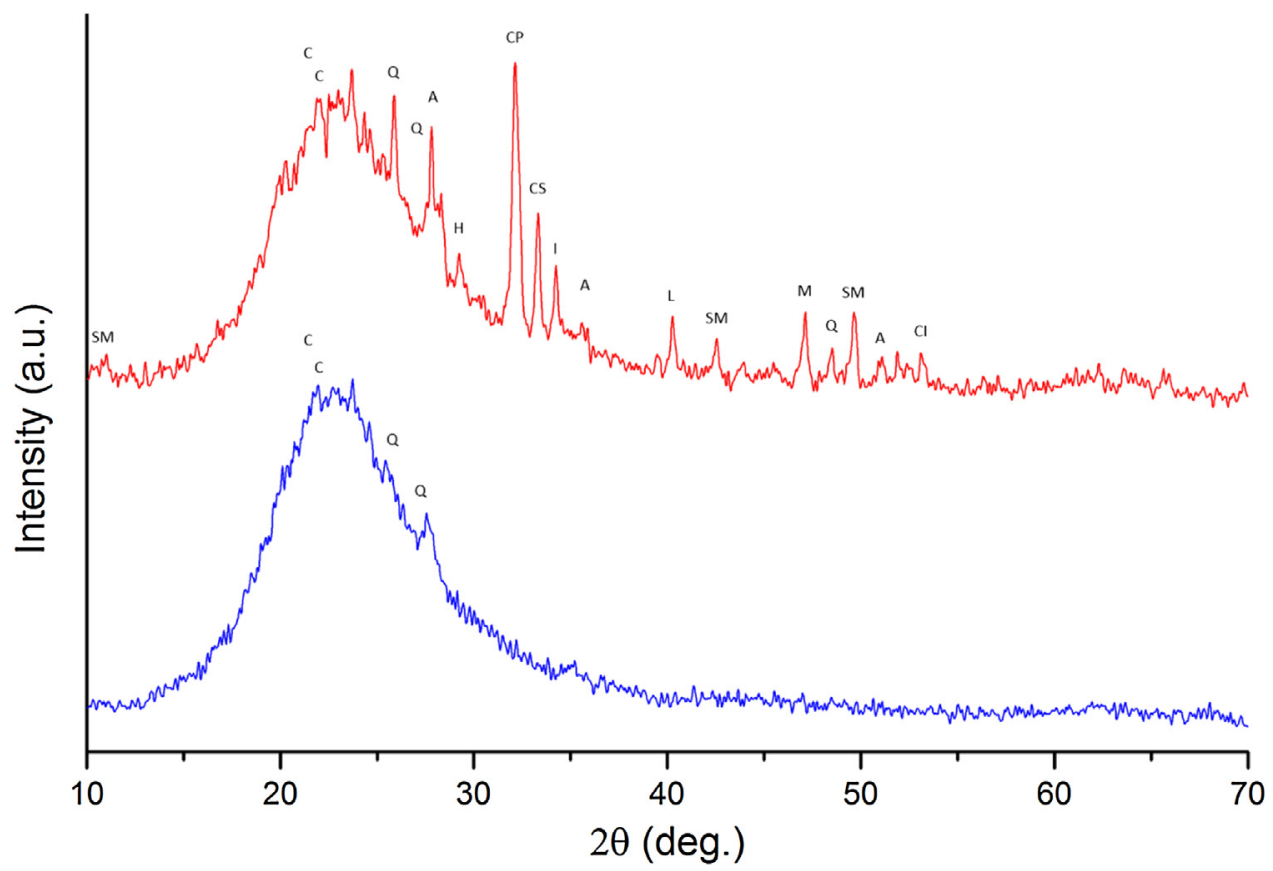

Fig. 3 - The XRD patterns: (A) the acid treated bio-silica particles; and (B) bio-silica-PDA-TEPA modified particles.

\begin{tabular}{lll}
$\begin{array}{l}\text { Table 2 } \\
\text { treated bio-silica. }\end{array}$ & \multicolumn{2}{c}{ Chemical composition of pristine and acid } \\
Equivalent compound & \multicolumn{2}{c}{ Content weight) } \\
\cline { 2 - 3 } & Pristine bio-silica & Acid treated bio-silica \\
\hline $\mathrm{SiO}_{2}$ & 66.90 & 80.54 \\
$\mathrm{CaO}$ & 7.08 & 0.90 \\
$\mathrm{Al}_{2} \mathrm{O}_{3}$ & 5.55 & 6.03 \\
$\mathrm{P}_{2} \mathrm{O}_{5}$ & 3.31 & - \\
$\mathrm{Fe}_{2} \mathrm{O}_{3}$ & 1.52 & 0.31 \\
$\mathrm{MgO}_{\mathrm{Na}} \mathrm{O}$ & 1.33 & 0.57 \\
$\mathrm{~K}_{2} \mathrm{O}$ & 0.65 & 0.38 \\
$\mathrm{TiO}_{2}$ & 0.65 & 0.28 \\
$\mathrm{Loss}$ of ignition & 0.29 & 0.19 \\
& 12.73 & 10.80 \\
\hline
\end{tabular}

hand, some changes were perceived on the surface of polydopamine and TEPA ligand grafted biosilica compared to acid treated counterpart. The TEPA-PDA grafted bio-silica surface became slightly smooth and the pores were seem to be filled by the grafted polymer and ligand. As seen from Table 2, silica $\left(\mathrm{SiO}_{2}\right)$ content of the acid treated bio-silica increased from 66.9 to $80.54 \%$ and, most of the unwanted impurities were eliminated by acid treatment such as $\mathrm{CaO}, \mathrm{Fe}_{2} \mathrm{O}_{3}, \mathrm{MgO}, \mathrm{Na}_{2} \mathrm{O}, \mathrm{K}_{2} \mathrm{O}$ and $\mathrm{TiO}_{2}$.

The phase match studies of XRD analysis are made based on the XRF characterization results. All phase identifications are performed using Match! a software package (Crystal Impact GbR, Bonn, Germany) supported by ICDD PDF-2 Powder Diffraction File as the reference database. Both XRD patterns of the pristine and acid treated diatomic earth showed a single band centered at about $23^{\circ} 2 \theta$ which indicate the amorphous silica phases (part of Fig. $3 \mathrm{~A}$ and $\mathrm{B}$ ). Additionally, the amorphous background, a significant amount of crystal phases can be seen from the XRD patterns of the pristine bio-silica. Some of the identified crystal phases from the pristine diatomic earth, with their abbreviations, are sodium magnesium phosphate $(\mathrm{SM})$, cristobalite $(\mathrm{C})$, quartz $(\mathrm{Q})$, albite $(\mathrm{A})$, hedenbergite $(\mathrm{H})$, calcium iron phosphate (CI), calcium sodium phosphate (CP), calcium sodium aluminum oxide (CS), imandrite (I), mag- nesium aluminum titanium oxide $(\mathrm{M})$, and loveringite $(\mathrm{L})$. However, diffraction peaks of existing impurities (SM, A, CP, $\mathrm{CS}, \mathrm{I}, \mathrm{A}, \mathrm{M}, \mathrm{CI})$ in the acid treated sample became weaker or disappear and just cristobalite $(C)$ and quartz $(\mathrm{Q})$ phases could be identified. It was observed that acid treatment did not form a remarkable crystalline form. XRD analysis indicates that the existing impurities is removed by acid treatment application.

\subsection{Adsorption studies of DB-74 dye on bio-silica preparations}

The maximum amount of DB-74 dye was obtained with the PDA-TEPA grafted bio-silica and suggested as an effective and stable adsorbent to remove the dye from aqueous medium. The preparation of bio-silica-PDA-TEPA particles was performed in two step process, in the first step pristine bio-silica was treated with $\mathrm{H}_{2} \mathrm{SO}_{4}$ solution and cleaned with purified water. In the second step, sequentially PDA and TEPA ligand grafted under alkaline condition. The TEPA ligand was attached via shift base reaction on the PDA modified bio-silica. The adsorption capacities of the acid treated, PDA grafted and PDA-TEPA grafted diatomic bio-silica particles for DB-74 dye were evaluated in a batch system. The adsorption capacities of the tested adsorbents for DB-74 dye were observed in the order of PDA-TEPA grafted $>$ PDA grafted $>$ acid treated. The maximum adsorption capacities of the tested adsorbents from initial $200 \mathrm{ppm}$ dye solution was found to be 32.2, 54.4 and $79.7 \mathrm{mg} \mathrm{g}^{-1}$ particles, respectively (Table S3). The adsorption capacity of the PDA-TEPA grafted bio-silica was nearly 2.5 -fold higher than the acid treated counterpart with an initial dye concentration of $200 \mathrm{mg} \mathrm{L}^{-1}$. The surface of the acid-treated bio-silica contains mainly $-\mathrm{OH}$ groups and that can permit only formation of hydrogen bonding with hydrogen donor site of the DB-74 dye molecules. The interaction between DB-74 dye and the PDA grafted bio-silica can be due to the exclusive hydrogen bonding, $\pi-\pi$ stacking interactions and electrostatic Coulombic interactions. Whereas the decoration of polyamine groups (i.e., TEPA ligand) on the PDA polymer grafted biosilica via shift base reaction generated a positively charged 


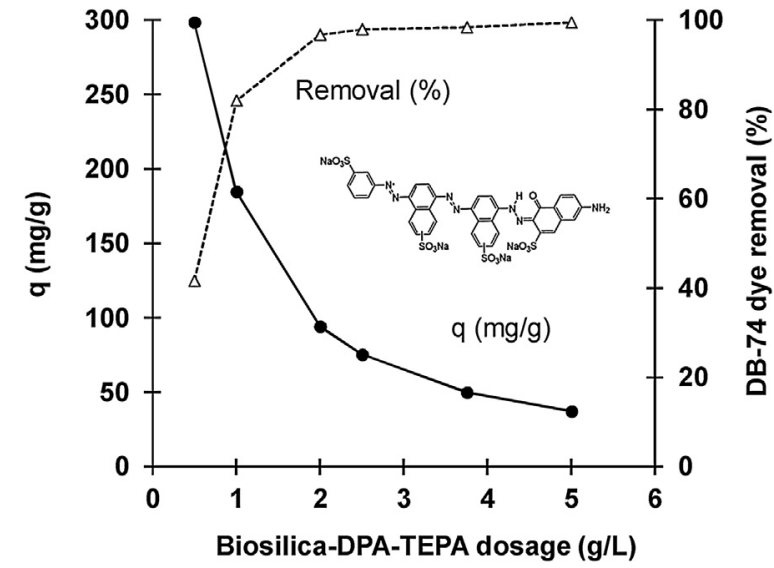

Fig. 4 - Effect of adsorbent amount on the adsorption of DB-74 dye on bio-silica-PDA (B) and bio-silica-PDA-TEPA particles.

surface. Thus, the additional five amine groups of the PDAgrafted bio-silica interacted with acidic sulfonate groups of the dye via ion-exchange interactions and, the absorption capacity of the PDA-TEPA grafted bio-silica increased about 2.5 folds compared to acid treated one. In this adsorbent system, TEPA ligand creates a polyamine focus for interactions with dye molecules, and significantly enhanced the adsorption capacity.

\subsection{Effect of the sorbent dose}

The adsorption rate of Direct Blue 74 was investigated by changing the dosage of TEPA-PDA-bio-silica from 0.5 to $5.0 \mathrm{gL}^{-1}$ and at $\mathrm{pH}$ 3.0. As can be seen from Fig. 4, the adsorption capacity increased after the dosage of bio-silicaTEPA-PDA particles was increased to $2.0 \mathrm{gL}^{-1} \mathrm{mg}(99.7 \%)$ due to the greater accessibility of surface binding sites with the increased dosage of TEPA-PDA-bio-silica. This observation can be explained by increasing of the available sites with increasing adsorbent dosage for the interaction with the dye, and lead in increases in the removal efficiency of DB-74 dye. Therefore, $2.0 \mathrm{gL}^{-1}$ was designated as the optimum TEPA-PDA-bio-silica dose and was used as a standard procedure for the remaining experimental studies. Similar observation have been reported by other authors (Park et al., 2017; Hassaninejad-Darzi et al., 2017; Das et al., 2017; Devi et al., 2017).

\subsection{Zeta-potential studies and effect of $\mathrm{pH}$ on $\mathrm{DB}-74$ adsorption}

In general, the medium $\mathrm{pH}$ has the highest effect on the removal performance of the adsorbents, and shows a significant role in ionization of useful groups on the sorbent surfaces (Gouthaman et al., 2018; Arica et al., 2017; Binaeian et al., 2018). Additionally, the medium $\mathrm{pH}$ could also affects the ionization of presence functional groups on dye, and accordingly the removal performance of the target molecule can be significantly affected (Gouthaman et al., 2018; Sadeghi-Kiakhani and Safapour, 2018; Binaeian et al., 2018). Before investigation of the effect of $\mathrm{pH}$ on the DB-74 dye adsorption, Zeta potential of the acid treated, PDA and TEPA-PDA grafted diatomic biosilica in the absence of DB-74 dye was studied by a Zeta Meter System as described above (Fig. 5). As can be seen from the figure, the Zeta potential value of the acid treated biosilica under different $\mathrm{pH}$ conditions was found to be negative

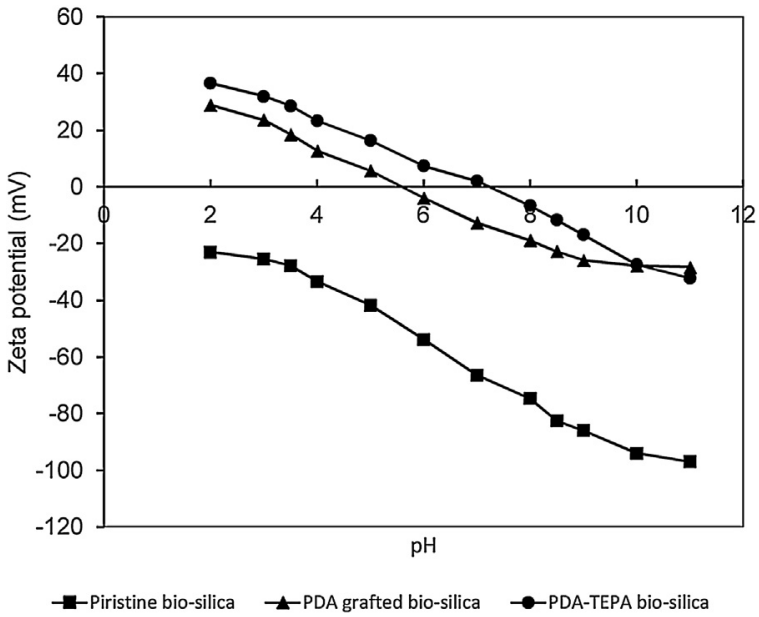

Fig. 5 - Zeta potentials of the pristine bio-silica (A), bio-silica-PDA (B) and bio-silica-PDA-TEPA (C) at different $\mathrm{pH}$ values.

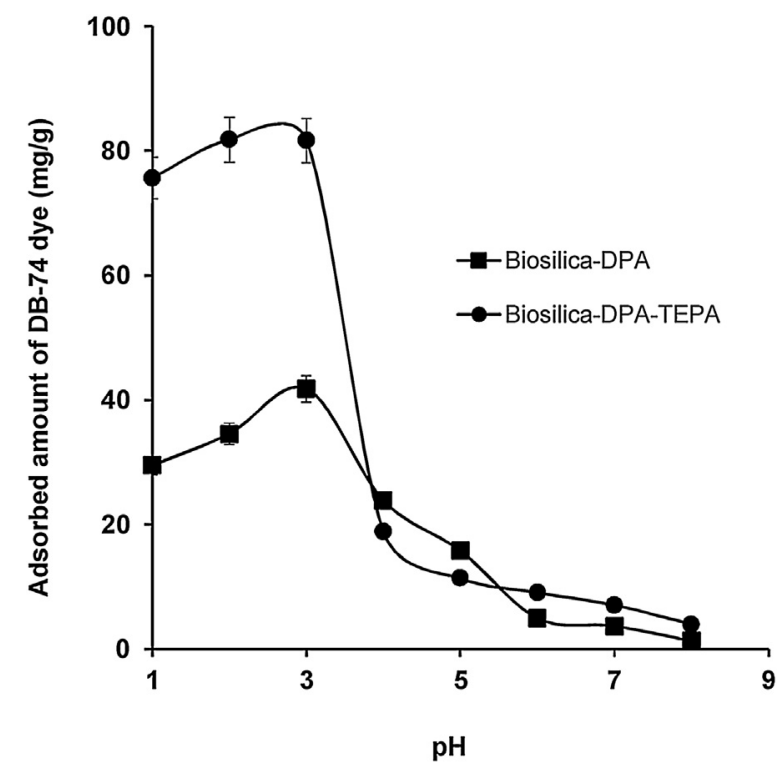

Fig. 6 - Effect of pH on the adsorption of DB-74 dye on bio-silica-PDA (B) and bio-silica-PDA-TEPA particles.

in the tested $\mathrm{pH}$ range $2.0-11.0$. It should be noted that the observed negative charge on the acid treated bio-silica can be due to the adjustable charge from the $\mathrm{pH}$ dependent surface hydroxyl sites (Fig. 5). On the other hand, the zero Zeta potential values for PDA and TEPA-PDA grafted diatomic biosilica were found to be around $\mathrm{pH} 5.5$ and 7.0, respectively. The zeta potential values of the acid treated, PDA and TEPA-PDA grafted diatomic bio-silica particles decreased progressively from -23.4 to $-97.2 \mathrm{mV}, 28.9$ to $-28.4 \mathrm{mV}$ and 36.6 to $-32.2 \mathrm{mV}$ when $\mathrm{pH}$ increased from 2.0 to 11.0, respectively (Fig. 5).

Fig. 6 depicts the effect of $\mathrm{pH}$ on the removal performance of the PDA and TEPA-PDA grafted diatomic bio-silica particles. The initial dye concentration was $200 \mathrm{mg} \mathrm{L}^{-1}$ and at $25^{\circ} \mathrm{C}$. From this figure, the adsorption capacities of the PDA and TEPA-PDA grafted bio-silica particles were increased from 29.5 to $41.8 \mathrm{mg} \mathrm{g}^{-1}$ and 69.7 and $81.7 \mathrm{mgg}^{-1}$ with the increase of $\mathrm{pH}$ values from 1.0 to 3.0 , respectively. On the other hand, the DB-74 adsorption by the PDA and TEPA-PDA grafted biosilica particles was increased over the $\mathrm{pH}$ ranges of 3.0-8.0. It should be noted that with further increase of $\mathrm{pH}$ the amount of adsorbed anionic dye DB-74 decreased in response to the 
decreasing number of positively charged sites of both PDA and TEPA-PDA grafted bio-silica particles due to the protonation of the amine groups. The deprotonation process take places. Thus, the TEPA ligand is deprotonated (i.e., $-\mathrm{NH}_{2}$ ) as the medium $\mathrm{pH}$ increases due to the $\mathrm{pKa}$ values of the amine groups are: $\mathrm{pKa}_{1}=9.68, \mathrm{pKa}_{2}=9.10, \mathrm{pKa}_{3}=8.08, \mathrm{pKa}_{4}=4.72$, and $\mathrm{pKa}_{5}=2.98$. The TEPA ligand attachment on the bio-silicaPDA caused generation of a primary and four secondary amine groups for each TEPA ligand (Table S1) and the adsorption performance of the TEPA grafted particles enhanced. Whereas dye molecule has four acidic sulfonate, a primary, a secondary and five tertiary amine groups. Thus, the adsorption amount of DB-74 on the PDA and PDA-TEPA grafted bio-silica can be affected by the presence of the amount of positive charges. The binding of DB-74 dye on both adsorbent should be a mixture of ion-exchange and hydrogen bonding interactions. The improved adsorption capacity of adsorbent from $\mathrm{pH} 1.0$ to 3.0 may be qualified to the negatively charged sulfate group ( $\mathrm{pKa}$ value 1.9) showing strong attraction for positively charged amino group's on adsorbents. Thus, the increasing $\mathrm{pH}$ from 3.0 to 8.0, the surfaces of the PDA and PDA-TEPA grafted biosilica became less positively charged, and the ion-exchange effect decreased accordingly the adsorption of the dye on both adsorbents decreased (Choi et al., 2017; Satilmis et al., 2017). For both adsorbents, the variation of the adsorption performance with $\mathrm{pH}$ were same with those of zeta potential values with $\mathrm{pH}$. Therefore, an assumption can be proposed that the generated additional positive charges on the adsorbent will present a higher adsorption capacity compared to unmodified version, due to the enforcement in electrostatic attraction between negatively charged DB-74 dye and positively charged adsorbent (Burakov et al., 2018). These observations were also correlated by the zeta potential studies (Zeng et al., 2017; Bayramoglu and Arica, 2018; Fan et al., 2018).

\subsection{Effect of presence salt on the removal efficiency of DB-74}

Textiles industrial effluents are containing dye with high salt concentration, and thus the increases the ionic strength values of the wastewater. Therefore, the ionic strength of the medium has been become an important parameter for the development of novel adsorbents (Debye and Hückel, 1923). To evaluate the effect of salt concentration on the adsorption efficiency of DB-74 on the bio-silica-PDA and bio-silica-PDATEPA particles was studied varying concentrations of $\mathrm{NaCl}$ in the range of $0.0-1.0 \mathrm{~mol} \mathrm{~L}^{-1}$. The removal percentage of the DB-74 dye on bio-silica-PDA was significantly affected by the ionic strength of the medium. On the other hand, the ionic strength of the medium did not affect adsorption behavior of the bio-silica-PDA-TEPA for the dye. As can be seen from Fig. 7, the adsorption behavior of the bio-silica-PDA and bio-silicaPDA-TEPA particles for adsorption of DB-74 dye was quite different and the adsorption performance of the bio-silicaPDA depended on the ionic strength of the medium. This can be explained by the electrical charge neutralization on both the bio-silica-PDA particles and dye molecules, water adsorption, and the salting out effect. As the ionic strength increased, the electrical double layer nearby the sorbent particles was compacted and steadily caused in a decrease in DB-74 removal performance of the bio-silica-PDA. However, the adsorption of DB-74 on the bio-silica-PDA-TEPA with increasing $\mathrm{NaCl}$ addition up to $1.0 \mathrm{~mol} \mathrm{~L}^{-1}$ did not affect the performance of the adsorbent. This can be due to the increases in the dimeriza-

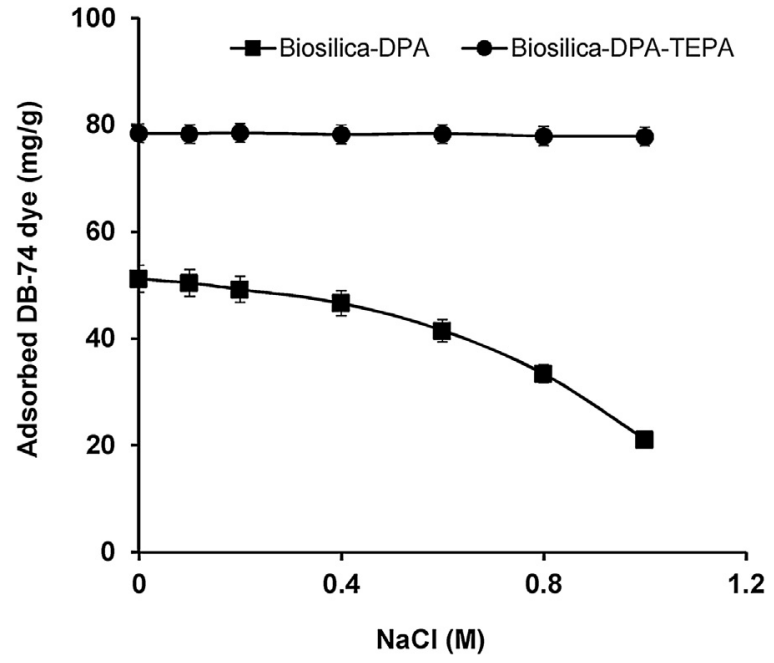

Fig. 7 - Effect of ionic strength on the adsorption of DB-74 dye on bio-silica-PDA (B) and bio-silica-PDA-TEPA particles.

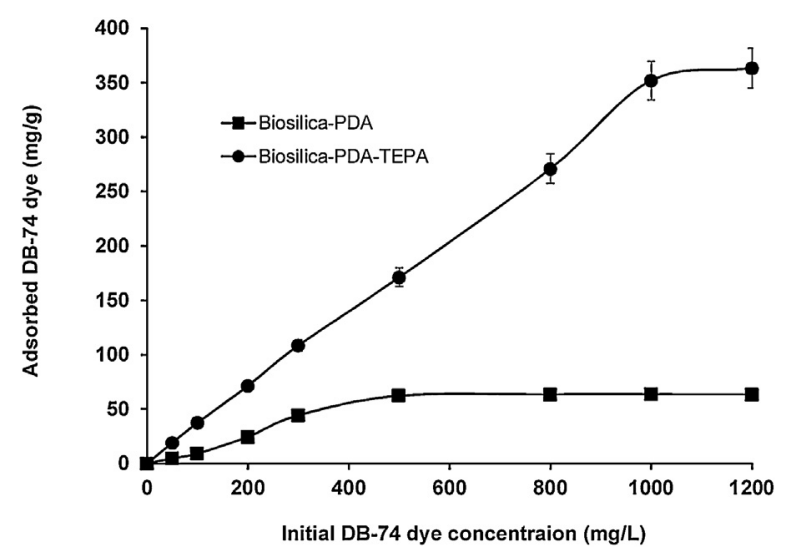

Fig. 8 - Effect of initial U(VI) concentration on the adsorption capacity of DB-74 dye on bio-silica-PDA (B) and bio-silica-PDA-TEPA particles.

tion or aggregation of DB-74 dye molecules, because of DB-74 dye molecules have several intermolecular forces such $-\mathrm{SO}_{3}$, $-\mathrm{HN}_{2},=\mathrm{NH}$ and hydrophobic groups. It has been reported that the interaction of these groups between each other can be increased upon addition of $\mathrm{NaCl}$ to the adsorption medium (Blanco et al., 2017; Kenawy et al., 2018; Ma et al., 2018; Alberghina et al., 2000).

\subsection{Effect of initial DB-74 dye concentration}

The effect of initial DB-74 concentration on the adsorption capacity of the bio-silica-PDA and bio-silica-PDA-TEPA particles is presented in Fig. 8. It should be noted that the interactions between DB-74 dye and bio-silica-PDA particles should be taken place electrostatic and hydrophobic interactions. Therefore, the negatively charged sulfate and hydrophobic groups of the dye molecules interact with positively charged amine and aromatic groups of the PDA grafted bio-silica particles. Whereas the bio-silica-PDA-TEPA particles have additional five amine groups and, thus, the ion-exchange interactions should be dominated between dye molecules and particles. As can be seen in Fig. 8, when the initial concentration of DB-74 dye increased in the solution, the amount of adsorbed dye on both adsorbents increased. For bio-silica-PDA, the amount of adsorbed dye increased from 4.7 to $64.5 \mathrm{mg} \mathrm{g}^{-1}$ as the initial concentrations of the DB-74 
Table 3 - Isotherm models constants and correlation coefficients for removal of DB-74 from aqueous medium on bio-silica-PDA and bio-silica-PDA-TEPA particles at $25^{\circ} \mathrm{C}$.

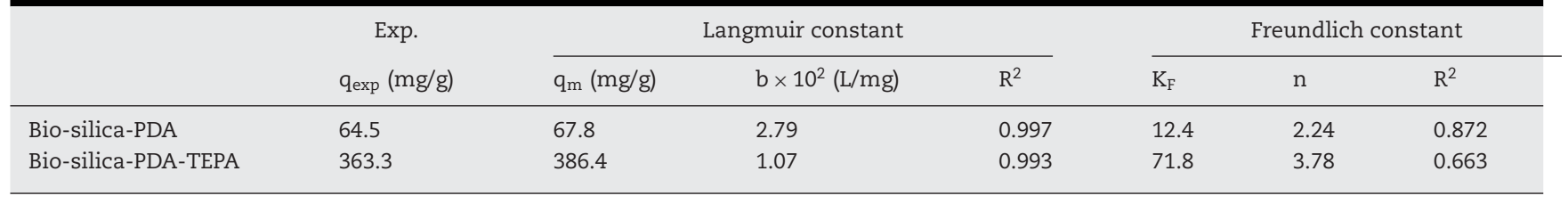

Table 4 - The first-order and second-order kinetics constants for removal of DB-74 from aqueous medium on

bio-silica-PDA and bio-silica-PDA-TEPA particles at $25^{\circ} \mathrm{C}$.

\begin{tabular}{|c|c|c|c|c|c|c|c|}
\hline & \multirow{2}{*}{$\frac{\operatorname{Exp}}{\mathrm{q}_{\mathrm{ex}}\left(\mathrm{mgg}^{-1}\right)}$} & \multicolumn{3}{|c|}{ First-order kinetic } & \multicolumn{3}{|c|}{ Second-order kinetic } \\
\hline & & $\mathrm{q}_{1, \mathrm{cal}}\left(\mathrm{mgg}^{-1}\right)$ & $\mathrm{k}_{1} \times 10^{2}\left(\min ^{-1}\right)$ & $\mathrm{R}^{2}$ & $\mathrm{q}_{2 \mathrm{q}, \mathrm{cal}}\left(\mathrm{mgg}^{-1}\right)$ & $\mathrm{k}_{2} \times 10^{3}\left(\mathrm{~g} \mathrm{mg}^{-1} \mathrm{~min}\right)$ & $\mathrm{R}^{2}$ \\
\hline Bio-silica-PDA & 64.5 & 23.5 & 2.81 & 0.946 & 68.9 & 1.13 & 0.993 \\
\hline Bio-silica-PDA-TEPA & 363.3 & 68.7 & 9.15 & 0.945 & 386.9 & 4.87 & 0.999 \\
\hline
\end{tabular}

dye increased from 50 to $1200 \mathrm{mg} \mathrm{L}^{-1}$. Under same conditions, the amount of adsorbed dye on the bio-silica-PDA-TEPA particles increased from 19.1 to $363.3 \mathrm{mg} \mathrm{L}^{-1}$. Thus, the adsorption capacity of the bio-silica-PDA-TEPA was found to be increased about 5.73 folds compared to bio-silica-PDA particles. Noted that, the amounts of dye adsorbed $\left(\mathrm{mgg}^{-1}\right)$ on both particles were significantly enhanced by increasing the initial dye concentration up to $1000 \mathrm{mgL}^{-1}$, then, they were reached a saturation at this dye concentration. This is due to the increase in the number of dye molecules per unit volume of the medium (Zeng et al., 2017). Thus, the number of binding sites for interaction of dye molecules becomes scarce for the increased amount of dye molecules in the adsorption medium. In conclusion, the incorporation of five positive net charges on the bio-silica-PDA particles yields a remarkable increase (more than 5.7 folds) in the adsorption capacity compared to TEPA ligand free counterpart.

\subsection{Effect of solution temperature on adsorption efficiency of adsorbents}

Effect of solution temperature on DB-74 adsorption efficiency of the bio-silica-PDA and bio-silica-PDA-TEPA particles was performed at four different temperatures (i.e., 5, 25, 35 and $45^{\circ} \mathrm{C}$ for $2.0 \mathrm{~h}$ (data not shown)). The amount of adsorbed DB-74 dye by both particles tested in this work seems to be independent of in the give temperature range. Similar observations have been reported by other researchers (Zeng et al., 2017).

\subsection{Adsorption isotherm studies}

The adsorption isotherm models could provide information about the surface properties and the adsorption performance of an adsorbant (Arsalani et al., 2018; Arica et al., 2017). The isotherm model also can propose valuable information about the interactions between the adsorbent surface and the target adsorbate. The Langmuir and Freundlich isotherm models were studied to describe the experimental data. Langmuir model is based on the assumption of surface uniformity and all adsorption sites on the surface of adsorbent are monolayer and homogeneous. On the other hand, the Freundlich model supposes that the multilayer of the adsorption process occurs on a heterogeneous surface and is applicable to heterogeneous systems (Bayramoglu et al., 2017; Ma et al., 2018). These two models are defined with the following equations:

$C_{e} / q_{e}=1 /\left(q_{m} \times b\right)+C_{e} / q_{m}$

$\log q_{e}=\log K_{F}+1 / n \log C_{e}$

For Langmuir model, the values of $q_{m}$ and $b$ which are calculated from slops and intercepts which represent maximum adsorption capacity and Langmuir constant, respectively. The $K_{F}$ and $n$ are the Freundlich constant and exponent, respectively. The $1 / n$ is a degree of the surface heterogeneity extending between 0.0 and 1.0, becoming more heterogeneous as its value gets closer to zero. The $\mathrm{q}_{\mathrm{m}}, \mathrm{b}, \mathrm{K}_{\mathrm{F}}$ and $\mathrm{n}$ values are determined from the linear isotherm plots and their values are presented in Table 3.

The correlation coefficients $\left(\mathrm{R}^{2}\right)$ of the Langmuir model (0.997 and 0.993 for the bio-silica-PDA and bio-silica-PDATEPA, respectively) are greater than those of the Freundlich model (0.872 and 0.663 , respectively), implying the adsorption of DB-74 on both adsorbents could well fit the Langmuir model (Table 3). Additionally, the maximum adsorption capacities of bio-silica-PDA and bio-silica-PDA-TEPA particles from the Langmuir model were found to be 67.8 and $386.4 \mathrm{mg} \mathrm{g}^{-1}$, respectively, these are very close the experimental data $(64.5$ and $386.4 \mathrm{mgg}^{-1}$ ). Generally, as the $\mathrm{K}_{\mathrm{F}}$ increases adsorption capacity of an adsorbent increases. If $\mathrm{n}<1.0, \mathrm{n}=1.0-2.0$ and $n=2.0-10.0$, define poor adsorption, reasonably difficult adsorption, and good adsorption, respectively. The calculated $\mathrm{n}$ values are greater than 2.0, indicating the favorable adsorption of the dyes onto both adsorbents. These results show that the Langmuir model was appropriate for describing the adsorption of the dye on the bio-silica-PDA and bio-silica-PDATEPA particles compared to the Freundlich model.

\subsection{Effect of contact time and adsorption kinetic analysis}

The contact time between the adsorbent and adsorbate has a great importance in economical point of view for the clarification of wastewaters. The adsorption contact time should be short as possible for any kind of highly operative sorbents utilized treatment of wastewaters (Zeng et al., 2017; Blanco et al., 2017). Fig. S4 displays the effect of the contact time on the adsorption efficiency of DB-74 dye on the both adsorbents with an initial concentration of dye $200 \mathrm{mg} \mathrm{L}^{-1}, \mathrm{pH} 2.0$, and at $25^{\circ} \mathrm{C}$. Under these conditions, the contact time was 
taken between 0.0 and $120 \mathrm{~min}$. As observed rom Fig. S4, the amount of adsorbed dye increased with increasing contact time for both adsorbents. The amount of adsorbed dye $\left(\mathrm{mg} \mathrm{g}^{-1}\right)$ onto the bio-silica-PDA and bio-silica-PDA-TEPA particles were found to be higher at the first $10.0 \mathrm{~min}$ and followed by a very steep adsorption curve up to $30 \mathrm{~min}$, and after that no important change in the amount of adsorbed DB-74 dye by adsorbents. The quick adsorption facility of the DB-74 on the bio-silica-PDA-TEPA particles could be due to the presence of four sulfate groups on the dye molecules. Noted that, at initial stage of adsorption process all the adsorptive sites are accessible for interacting with dye molecules, and thus, leading to a short adsorption time for interaction with the dye molecules. After this time period, the dye molecules have to compete with each other to contact with the adsorptive sites of the adsorbents, and the adsorption process becomes slow down. Then, the system reaches an adsorption equilibrium time. A contact time of 120 min was selected as optimal time to guarantee that equilibrium is reached for the experiments within the scope of this study.

The adsorption kinetics of the DB-74 dye on the bio-silicaPDA and bio-silica-PDA-TEPA particles were assessed by the pseudo first- and pseudo second-order kinetic models. The equations are:

$\log \left(q_{e q}-q_{t}\right)=\log q_{1 \mathrm{cal}}-\left(k_{1} t / 2.303\right)$

$t / q_{t}=\left(1 / k_{2} q^{2} 2\right.$ cal $)+\left(1 / q_{2 c a l}\right) t$

where $\mathrm{q}_{2 \text { cal }}$ is the adsorption capacity calculated from the pseudo-second order equation $\left(\mathrm{mg} \mathrm{g}^{-1}\right)$.

As can be seen from Table 4, for the pseudo-second-order kinetic model, the correlation coefficient $\left(R^{2}\right)$ values were higher than those for the pseudo first-order kinetic model for both tested adsorbents. An addition, the equilibrium adsorption capacity values calculated from the pseudo-second order model were in agreement with the experimental data. These results indicates that the reversible adsorption process could be well designated by the pseudo-second-order model for adsorption of DB-74 dye on the bio-silica-PDA and bio-silicaPDA-TEPA particles. Noted that the ion-exchange sites and lone pair of electrons on surface functional groups of the adsorbents involve in the adsorption process. These functional groups (i.e., hydroxyl, primary and secondary amine, sulfate groups and hydrophobic entities) government the adsorption process.

\subsection{Desorption and reusability studies}

The reusability of an adsorbent is a significant parameter from economic point of view. Therefore, the reuse performance of a newly designed adsorbent is important for treatment of large volume of wastewaters (Binaeian et al., 2018; Arica et al., 2017; Gouthaman et al., 2018). The presented novel cationic biosilica-PDA-TEPA adsorbent is highly stable to various harsh conditions (such as extreme $\mathrm{pH}$ and temperature), additionally, it is resistant to microbial attack and many chemicals, and can be used for removal of many organic and inorganic pollutants from water bodies. For reusability of the bio-silicaPDA-TEPA particles, the adsorbed dye could be desorbed under appropriate conditions. As presented above, the adsorbed amount of DB-74 dye was drastically decreased under alkali conditions for both tested adsorbents. For this reason, the dye laden adsorbent was emptied using $\mathrm{NaOH}$ solution $(50 \mathrm{mM}, \mathrm{pH}$

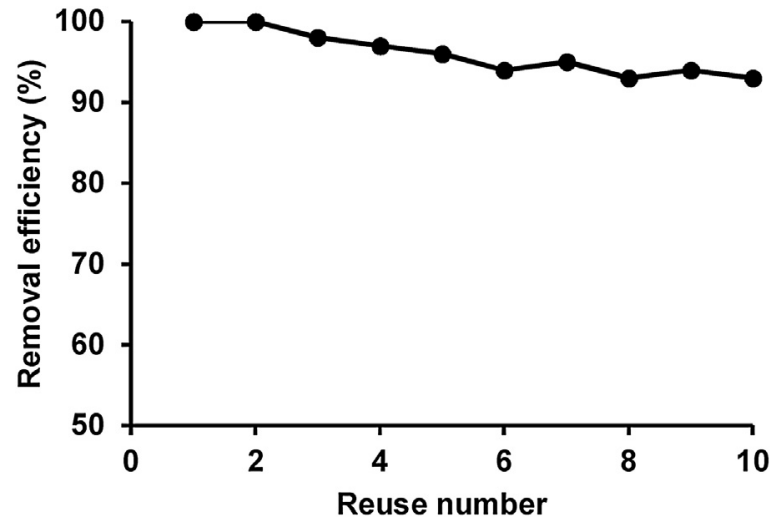

Fig. 9 - Reusability of the bio-silica-PDA-TEPA particles for the removal of DB-74 dye.

10). It should be noted the de-protonation of the amine groups under basic conditions permit the release of the adsorbed dye. Under given experimental protocols, more than $95 \%$ of the dye was eluted. The repeated use of the bio-silica-PDA-TEPA particles was evaluated over ten consecutive cycles, and a 7\% decrease in the initial adsorption capacity was observed at the end of ten adsorption/desorption cycles (Fig. 9). It can be concluded that the presented novel green adsorbent can be successfully used as a proper and cheap adsorbent for removal of pollutants with a high adsorption capacity.

\section{Conclusions}

The acid treated diatomic bio-silica particles have been easily prepared through oxidation polymerization of dopamine on the surface of the acid treated bio-silica. Then, a polyamine ligand TEPA was covalently attached on the PDA grafted bio-silica via shift base coupling. ATR-FTIR, XRD, SEM, BET, Zeta-potential analysis and analytical methods were used to characterization of the adsorbents. The experimental studies show that the DB-74 adsorption was highly dependent on medium initial $\mathrm{pH}$ and initial dye concentration. The adsorption capacity of the biosilica-PDA-TEPA particles towards DB-74 dye was found to be $363.3 \mathrm{mgg}^{-1}$, which was larger than that of the many adsorbents. For examples, silica gel functionalized with 2,2-(pentane-1,5-diylbis(oxy)) dibenzaldehyde was used for removal of Reactive Blue 19 and Reactive Yellow 84, the adsorption capacity was $37.45 \mathrm{mgg}^{-1}$ and $32.36 \mathrm{mg} \mathrm{g}^{-1}$, respectively (Banaei et al., 2017). Another study, monoamine modified silica particles were used for adsorption of acid orange 10 and acid orange 12 and the reported adsorption capacity was 13.5 and $39.2 \mathrm{mgg}^{-1}$, respectively (Donia et al., 2009). On the other hand, an amine functionalized mesoporous silica was used for removal of phenol red and alizarin yellow and the maximum adsorption capacity of the adsorbent was reported as 370.7 and $400.0 \mathrm{mgg}^{-1}$, respectively (Adlnasa et al., 2017), and the later result was compatible with this work. The DB-74 adsorption on biosilica-PDA-TEPA particles is 5.73 times greater than that of the acid treated bio-silica. The equilibrium data were compatible with the Langmuir model well, and the maximum adsorption capacity of the DB-74 dye onto bio-silica-PDA-TEPA particles was $386.4 \mathrm{mg} \mathrm{g}^{-1}$. The adsorption of DB-74 dye onto the biosilica-PDA-TEPA particles followed the pseudo-second-order kinetic model due to the theoretical absorption capacity of pseudo-second-order model is very close to the experimental adsorption capacity. It should be noted the natural and envi- 
ronmentally friendly PDA-TEPA particles have several desired properties such non-toxicity, easy preparation, high adsorption capacity, instantaneous removal of micro-pollutants and high regeneration capability. Thus, they have a great potential as a cheap adsorbent for removal of organic pollutant from aqueous medium. Additionally, the fabricated bio-silicaPDA-TEPA particles can be also used as an efficient adsorbent for treating industrial effluents containing heavy metals ions such as lead or mercury.

\section{Appendix A. Supplementary data}

Supplementary data associated with this article can be found, in the online version, at https://doi.org/10.1016/j.cherd. 2018.11.003.

\section{References}

Adlnasa, L., Shabanian, M., Ezoddin, M., Maghsodi, A., 2017. Amine rich functionalized mesoporous silica for the effective removal of alizarin yellow and phenol red dyes from waste waters based on response surface methodology. Mater. Sci. Eng. B 226, 188-198.

Aksu, Z., Karabayır, G., 2008. Comparison of biosorption properties of different kinds of fungi for the removal of Gryfalan Black RL metal-complex dye. Bioresour. Technol. 99, 7730-7741.

Alberghina, G., Bianchini, R., Fichera, M., Fisichella, S., 2000. Dimerization of Cibacron Blue F3GA and other dyes: influence of salts and temperature. Dyes Pigm. 46, 129-137.

Arica, T.A., Ayas, E., Arica, M.Y., 2017. Magnetic MCM-41 silica particles grafted with poly(glycidylmethacrylate) brush: modification and application for removal of direct dyes. Micropor. Mesopor. Mater. 243, 164-175.

Arsalani, N., Nasiri, R., Zarei, M., 2018. Synthesis of magnetic 3D graphene decorated with $\mathrm{CaCO}_{3}$ for anionic azo dye removal from aqueous solution: kinetic and RSM modeling approach. Chem. Eng. Res. Des. 136, 795-805.

Banaei, A., Ebrahimi, S., Vojoudi, H., Karimi, S., Badiei, A., Pourbasheer, E., 2017. Adsorption equilibrium and thermodynamics of anionic reactive dyes from aqueous solutions by using a new modified silica gel with 2,2-(pentane-1,5-diylbis(oxy))dibenzaldehyde. Chem. Eng. Res. Des. 123, 50-62.

Bayramoglu, G., Akbulut, A., Arica, M.Y., 2017. Removal of metal complexed azo dyes from aqueous solution using tris(2-aminoethyl)amine ligand modified magnetic p(GMA-EGDMA) cationic resin: adsorption, isotherm and kinetic studies. Chem. Eng. Res. Des. 124, 85-97.

Bayramoglu, G., Arica, M.Y., 2018. Adsorption of Congo Red dye by native amine and carboxyl modified biomass of Funalia trogii: isotherms, kinetics and thermodynamics mechanisms. Korean J. Chem. Eng. 35, 1303-1311.

Binaeian, E., Tayebi, H.-A., Rad, A.S., Afrashteh, S., 2018. Adsorption of acid blue on synthesized polymeric nanocomposites, PPy/MCM-41 and PAni/MCM-41: isotherm, thermodynamic and kinetic studies. J. Macromol. Sci. A 55, 269-279.

Blanco, S.P.D.M., Scheufele, F.B., Módenes, A.N., Espinoza-Quiñones, F.R., Marin, P., Kroumov, A.D., Borba, C.E., 2017. Kinetic, equilibrium and thermodynamic phenomenological modeling of reactive dye adsorption onto polymeric adsorbent. Chem. Eng. J. 307, 466-475.

Boukoussa, B., Hakiki, A., Moulai, S., Chikh, K., Kherroub, D.E., Bouhadjar, L., Guedal, D., Messaoudi, K., Mokhtar, F., Hamacha, R., 2018. Adsorption behaviors of cationic and anionic dyes from aqueous solution on nanocomposite polypyrrole/SBA-15. J. Mater. Sci. 53, 7372-7386.

Burakov, A.E., Galunin, E.V., Burakov, I.V., Kucherova, A.E., Agarwal, S., Tkachev, A.G., Gupta, V.K., 2018. Adsorption of heavy metals on conventional and nanostructured materials for wastewater treatment purposes: a review. Ecotoxicol. Environ. Saf. 148, 702-712.

Cao, D., Cheng, W., Tao, K., Liang, Y., 2018. Preparation of polydopamine-modified 3D interconnected macroporous silica for laccase immobilization. Macromol. Res. 26, 616-622.

Choi, B.H., Jung, K.-W., Choi, J.-W., Lee, S.-H., Lee, Y.J., Ahn, K.-H., 2017. Facile one-pot synthesis of imidazole-functionalized poly-(vinylbenzyl chloride) and its study on the applicability of synthetic dye removal from aqueous system. J. Clean. Prod. 168, 510-518.

Das, S., Chakraborty, P., Ghosh, R., Paul, S., Mondal, S., Panja, A., Nandi, A.K., 2017. Folic acid-polyaniline hybrid hydrogel for adsorption/reduction of chromium (VI) and selective adsorption of anionic dye from water. ACS Sustainable Chem. Eng. 5, 9325-9337.

Debye, P., Hückel, E., 1923. The theory of electrolytes. I. Lowering of freezing point and related phenomena. Phys. Z. 24, 185-206.

Devi, V., Selvaraj, M., Selvam, P., Ashok Kumar, A., Sankar, S., Dinakaran, K., 2017. Preparation and characterization of CNSR functionalized $\mathrm{Fe}_{3} \mathrm{O}_{4}$ magnetic nanoparticles: an efficient adsorbent for the removal of cadmium ion from water. J. Environ. Chem. Eng. 5, 4539-4546.

Donia, A.M., Atia, A.A., Al-amrani, W.A., El-Nahas, A.M., 2009. Effect of structural properties of acid dyes on their adsorption behaviour from aqueous solutions by amine modified silica. J. Hazard. Mater. 161, 1544-1550.

Fan, Y.-H., Zhang, S.-W., Qin, S.-B., Li, X.-S., Qi, S.-H., 2018. An enhanced adsorption of organic dyes onto $\mathrm{NH}_{2}$ functionalization titanium-based metal-organic frameworks and the mechanism investigation. Micropor. Mesopor. Mater. 263, 120-127.

Gao, Y., Kaziem, A.E., Zhang, Y., Xiao, Y., He, S., Li, J., 2018. A hollow mesoporous silica and poly(diacetone acrylamide) composite with sustained-release and adhesion properties. Micropor. Mesopor. Mater. 255, 15-22.

Ghasemi, S., Karim, S., 2018. Controlled synthesis of modified polyacrylamide grafted nano-sized silica supported Pd nanoparticles via RAFT polymerization through grafting to approach: application to the Heck reaction. Colloid Polym. Sci. 296, 1323-1332.

Gouthaman, A., Azarudeen, R.S., Gnanaprakasam, A., Sivakumar, V.M., Thirumarimurugan, M., 2018. Polymeric nanocomposites for the removal of Acid red 52 dye from aqueous solutions: synthesis, characterization, kinetic and isotherm studies. Ecotoxicol. Environ. Saf. 160, 42-51.

Grommersch, B.M., Pant, J., Hopkins, S.P., Goudie, M.J., Handa, H., 2018. Biotemplated synthesis and characterization of mesoporous nitric oxide-releasing diatomaceous earth silica particles. ACS Appl. Mater. Interfaces 10, 2291-2301.

Hassaninejad-Darzi, S.K., Mousavi, H.Z., Ebrahimpour, M., 2017. Biosorption of Acridine Orange and Auramine $\mathrm{O}$ dyes onto MCM-41 mesoporous silica nanoparticles using high-accuracy UV-Vis partial least. J. Mol. Liq. 248, 990-1002.

Ibupoto, A.S., Qureshi, U.A., Ahmed, F., Khatri, Z., Khatri, M., Maqsooda, M., Brohi, R.Z., Kim, I.S., 2018. Reusable carbon nanofibers for efficient removal of methylene blue from aqueous solution. Chem. Eng. Res. Des. 136, 744-752.

Jiang, Y., Zhai, J., Zhou, L., He, Y., Ma, L., Gao, J., 2018. Enzyme@silica hybrid nanoflowers shielding in polydopamine layer for the improvement of enzyme stability. Biochem. Eng. J. 132, 196-205.

Kenawy, I.M.A.M., El-Reash, Y.G.A., Hassanien, M.M., Alnagar, N.R., Mortada, W.I., 2018. Use of microwave irradiation for modification of mesoporous silica nanoparticles by thioglycolic acid for removal of cadmium and mercury. Micropor. Mesopor. Mater. 258, 217-227.

Knoerr, R., Brendle, J., Lebeau, B., Demais, H., 2013. Preparation of ferric oxide modified diatomite and its application in the remediation of As(III) species from solution. Micropor. Mesopor. Mater. 169, 185-191. 
Konicki, W., Hełminiak, A., Arabczyk, W., Mijowska, E., 2018. Adsorption of cationic dyes onto Fe@graphite core-shell magnetic nanocomposite: equilibrium, kinetics and thermodynamics. Chem. Eng. Res. Des. 129, 259-270.

Li, L., Wang, H., Zhang, Z., Chen, X., Li, Q., 2017. Facile synthesis of bioglass nanospheres for the adsorption of cationic and anionic dyes from aqueous solution. J. Disper. Sci. Technol. 38 $1711-1718$.

Liu, C., Omer, A.M., Ouyang, X.-K., 2018. Adsorptive removal of cationic methylene blue dye using carboxymethyl cellulose/k-carrageenan/activated montmorillonite composite beads: isotherm and kinetic studies. Int. J. Biol. Macromol. 106, 823-833.

Ma, H., Pu, S., Hou, Y., Zhu, R., Zinchenko, A., Chu, W., 2018. A highly efficient magnetic chitosan "fluid" adsorbent with a high capacity and fast adsorption kinetics for dyeing wastewater purification. Chem. Eng. J. 345, 556-565.

Messersmith, P.B., Lee, H., Dellatore, S.M., Miller, W.M., 2007. Mussel-inspired surface chemistry for multifunctional coatings. Science 318, 426-430.

Mondal, P., Baksi, S., Bose, D., 2017. Study of environmental issues in textile industries and recent wastewater treatment technology. WSN 61, 98-109.

Park, H.N., Cho, C.-W., Choi, H.A., Won, S.W., 2017. Polyethylenimine-coated polysulfone/bacterial biomass composite fiber as a biosorbent for the removal of anionic dyes: optimization of manufacturing conditions using response surface methodology. Korean J. Chem. Eng. 34, 2519-2526.

Rahouia, N., Jianga, B., Hegazy, M., Taloub, N., Wang, Y., Yu, M., Huang, Y.D., 2018. Gold modified polydopamine coated mesoporous silica nano-structures for synergetic chemo-photothermal effect. Colloid Surf. B 171, 176-185.

Sadeghi-Kiakhani, M., Safapour, S., 2018. Salt-free dyeing of cotton fabric modified with prepared chitosan-poly (propylene) imine dendrimer using direct dyes. Prog. Color Colorants Coat. 11, 21-32.
Satilmis, B., Budd, P.M., Uyar, T., 2017. Systematic hydrolysis of PIM-1 and electrospinning of hydrolyzed PIM-1 ultrafine fibers for an efficient removal of dye from water. React. Funct. Polym. 121, 67-75.

Srinivasan, A., Viraraghavan, T., 2010. Decolorization of dye wastewaters by biosorbents: a review. J. Environ. Manage. 91, 1915-1929.

Vojoudi, H., Badiei, A., Amiri, A., Banaei, A., Ziarani, G.M., Schenk-Joß, K., 2018. Efficient device for the benign removal of organic pollutants from aqueous solutions using modified mesoporous magnetite nanostructures. J. Phys. Chem. Solids $113,210-219$

Wang, Y., Du, T., Zhou, L., Song, Y., Che, S., Fang, X., 2018. Removal of Acid Red $G$ dye from aqueous solutions by adsorption to MCM-41-layered double hydroxides composite. Korean J. Chem. Eng. 35, 709-716.

Xiong, B., Wang, N., Chen, Y., Peng, H., 2018. Self-assembly of alginate/polyethyleneimine multilayer onto magnetic microspheres as an effective adsorbent for removal of anionic dyes. J. Appl. Polym. Sci. 135, 45876.

Xu, L.Q., Neoh, K.-G., Kang, E.-T., 2018. Natural polyphenols as versatile platforms for material engineering and surface functionalization. Prog. Polym. Sci. 87, 165-196.

Yang, C., Yu, L., Chen, R., Cheng, J., Chen, Y., Hu, Y., 2017. Congo red adsorption on metal-organic frameworks, MIL-101 and ZIF-8 Kinetics, isotherm and thermodynamic studies. Desalin. Water Treat. 94, 211-221.

Zeng, G., Ye, Z., He, Y., Yang, X., Ma, J., Shi, H., Feng, Z., 2017. Application OF dopamine-modified halloysite nanotubes/pvdf blend membranes FOR direct dyes removal FROM wastewater. Chem. Eng. J. 323, 572-583.

Zhang, B., Huyan, Y., Wang, J., Chen, X., Zhang, H., Zhang, Q., 2018. $\mathrm{Fe}_{3} \mathrm{O}_{4} @ \mathrm{SiO}_{2} @ \mathrm{CCS}$ porous magnetic microspheres as adsorbent for removal of organic dyes in aqueous phase. J. Alloys Compd. 735, 1986-1996. 